\title{
Correspondence
}

To the Editors

\section{A teacher as a member of the paediatric team: lessons to put into action}

Sri Lanka Journal of Child Health, 2008: 37: 149-50

For effective paediatric care a multi-disciplinary team is essential. The differing skills and abilities of professionals complement each other in delivering optimal health care to the child and his/her family. For several decades play has been an accepted form of treatment for developmental and behavioural problems, but its therapeutic value in the management of physical illness is more recent ${ }^{1,2,3}$. The assistance of a play leader is not a strategy widely used in paediatric practice in Sri Lanka.

This letter describes the interactive work of a hospital-based teacher who performed the role of play leader, child minder, class teacher, counsellor, therapist and friend.

A primary school teacher with training in special education was attached to a busy tertiary care unit, the professorial paediatric ward at the Lady Ridgeway Hospital for Children, Colombo. In addition to her central role in the playroom she was a team member in the weekly child development clinic. Some highlights of her experience, which spans twenty four years, are listed below.

\section{Helping adjustments to hospital stay}

Hospitalization is emotionally challenging for children. Using a variety of play and art techniques the teacher was able to alleviate emotional and psychological problems. The playroom with its array of toys, games and books was effective in making hospital stay pleasant and more pleasurable.

\section{Obtaining co-operation}

The value of toys is often forgotten and not apparent in many paediatric wards, clinics and waiting rooms in Sri Lanka. On numerous occasions the playroom and its play leader helped obtain the co-operation for unpleasant procedures and treatment modalities. This was useful in management of both acutely ill, short stay and long stay patients.

\section{Facilitating return to hospital}

Links established with the teacher were helpful during readmission to hospital.
Parents of children needing recurrent hospital admission with long standing illnesses such as nephrotic syndrome and thalassaemia, reported that memories of play within the hospital and reunion with the 'teacher' facilitated return to hospital, for further treatment.

\section{Pain management}

Playing games, listening to stories, and art therapy helped children cope with physical and emotional pain. Attending the playroom benefited children with conditions varying from arthritis to child abuse.

\section{Child minding during sibling visits}

The teacher eased the burden of many mothers who needed a child minder for healthy siblings who accompanied a sick child to hospital. By filling this void, she improved compliance with hospital admission.

\section{Encouraging return to school}

Providing classroom activities in the ward helped long stay children keep in touch with their school work. This helped the child to return to school, minimizing anxieties and reluctance to do so -an aspect of 'total care' easily forgotten by clinicians.

\section{Family centred psychological support}

Strong bonds of friendship developed between the 'teacher' and children with recurrent admissions. This was especially evident among those having thalassaemia or haemophilia.

The emotional links formed with the teacher, over many years of acquaintance, was often stronger than those with junior doctors whose individual term of work lasts only for a period of six months or one year. Therefore at times of bereavement the teacher was able to help families significantly.

Parents often sought the teacher when they needed someone to talk to. Her being a non-medical person was felt to have had its advantages in certain situations. 
Assessment of child development

A teacher trained in special education is an essential team member in delivering child development services. By providing her expertise in a play environment, it was possible to assess children in a more natural setting.

Remedial therapy for developmentally delayed

Books, pictures, toys, games, puzzles and information for home-based programmes were effectively distributed. Conducting group therapy sessions and providing advice on delivering remedial therapy were among her activities.

Toy making sessions

Toy making sessions for parents using low cost material was another activity through which the teacher was able to help children.

Toy lending library

Her expertise in skills analysis and deciding on the appropriateness of a toy for a given child maximized the usefulness of the toy lending library, which she administered. The toy lending library improved attention, language and listening skills, hand-use etc. through structured and educational toys.

\section{Helping obtain resources}

Directing parents to resources available in the community for the handicapped was another activity the teacher engaged in.

Liaison between education services and hospital

Teachers in a school environment are often those who identify developmental problems. By facilitating information flow between the hospital and school authorities, the teacher fulfilled a very useful link.
We hope that the experience documented here would broaden the multi-professional management of sick children, by breaking down professional boundaries in clinical settings.

\section{Acknowledgements}

We are grateful to Prof. Priyani Soysa who recruited Mrs. S Jayasinghe, to Prof. Sanath Lamabadusuriya and St. Luke's Church for their continued support of this project.

\section{References}

1. Lear R. Play helps: toys and activities for handicapped children. London: Heinemann Medical Books; 1977.

2. Grantham-McGregor S. Importance of Play Child Health Dialogue 1996; 5:9.

3. Zahir M, Bennett S. Review of Child development teams. Arch Dis Child 1994; 70: 224-7.

\section{S M Senanayake}

Demonstrator, Department of Paediatrics, Faculty of Medicine, University of Colombo.

\section{Sushila Jayasinghe}

Teacher in special education, Professorial Paediatric Unit, Lady Ridgeway Hospital, Colombo.

\section{P Senanayake}

Professor, Department of Paediatrics, Faculty of Medicine, University of Colombo. 